\title{
Source of Raised Serum Estrogens in Male Rats with Portal Bypass
}

\author{
Geoffrey C. Farrell, Agnes Koltai, and Michael Murray \\ Department of Medicine, The University of Sydney and Westmead Hospital, Westmead, New South Wales, Australia 2145
}

\begin{abstract}
We sought to establish the mechanism for the raised serum estrogen levels that occur in male rats with portal hypertension and resultant portal bypass. Using the portal vein ligated (PVL) rat model, we evaluated plasma steroid hormone concentrations, metabolic clearance rate (MCR) of estradiol, and hepatic metabolism of androstenedione to estrogens and other products. In contrast to serum testosterone levels that were reduced, serum androstenedione levels were normal in the PVL rat. Estradiol MCR was measured by a constant intravenous infusion technique and was found to be similar in PVL and control animals. Androstenedione MCR was determined during constant intravenous infusion of $\left[{ }^{3} \mathrm{H}\right]$ androstenedione, and the resultant radiolabeled steroids present in plasma were separated by thin layer chromatography. The MCR of androstenedione was not diminished in PVL rats compared with controls. However, there was a sevenfold increase in the plasma estradiol derived from $\left[{ }^{3} \mathrm{H}\right]$ androstenedione in rats with portal bypass. Examination of radiolabel excreted in bile during infusion of $\left[{ }^{3} \mathrm{H}\right]$ androstenedione showed that $25-46 \%$ of this steroid was converted to estradiol in PVL rats compared with $<3 \%$ in control male rats $(P<0.001)$. Moreover, there was a selective reduction in the excretion of $16 \alpha$-hydroxyandrostenedione, a finding which suggested that the metabolism of androstenedione via this pathway was decreased. Androstenedione $16 \alpha$-hydroxylation is known to be catalyzed by a malespecific cytochrome $P-450$ isoform, $P-450_{U T-A}$. We conclude that raised plasma estradiol levels after portal bypass in male rats are due to increased production rates, resulting in turn from enhanced aromatization of androstenedione to estradiol. On the basis of the observed specific changes in androstenedione hydroxylation pathways, it is proposed that alterations in levels of sex-specific forms of cytochrome $P-450$ occur in male rats with portal bypass and could account for the enhanced formation of estradiol.
\end{abstract}

\section{Introduction}

Portal bypass is a pathophysiologic state in which splanchnic blood is diverted from the liver to enter the systemic circulation directly. It may occur due to surgical creation of a portacaval shunt or because of an obstruction to flow through the

Address all correspondence to Dr. G. C. Farrell, Department of Medicine, The University of Sydney and Westmead Hospital, Westmead, New South Wales, Australia 2145. 1987.

Received for publication 11 July 1986 and in revised form 18 May

J. Clin. Invest.

(c) The American Society for Clinical Investigation, Inc.

$0021-9738 / 88 / 01 / 0221 / 08 \quad \$ 2.00$

Volume 81, January 1988, 221-228 portal venous system leading to portal hypertension and the resultant development of portasystemic venous anastomoses. The latter situation occurs in cirrhotic liver disease $(1,2)$ and can also be produced experimentally by occlusions of the portal vein $(3,4)$. Irrespective of its cause, portal bypass is associated with liver atrophy and a variety of metabolic changes (3-7). One such change is a reduced level of hepatic microsomal cytochrome $P-450$, a key component of mixed function oxidase enzymes concerned with the metabolism of foreign compounds and of steroid hormones (4, 5, 8-10).

Recent investigations have established that reduced hepatic mixed-function oxidase activity after portal bypass occurs only in intact male rats; reduced activity was not apparent in microsomes from castrated male or from female rats subjected to portal bypass $(10,11)$. Moreover, the lowering of mixed function oxidase activities was confined to those enzymes that display a striking sex dependence, being severalfold more active in male than in female rat liver microsomes $(11,12)$. Using a simple rat model of portal bypass, the portal vein ligated $(P V L)^{1}$ rat, it was also observed that changes in drug metabolising enzymes were associated with testicular atrophy (11). Serum testosterone concentrations were decreased concomitantly in this and in other models of portal bypass in rats $(10,11,13)$. Levels of serum luteinizing hormone were also reduced in these animals $(11,13)$, a finding that is consistent with altered hypothalamic-pituitary regulation of sex hormone metabolism.

Hyperestrogenism and feminization are prominent clinical features in humans with chronic liver disease (14-17). It is therefore of considerable interest that the changes in testicular size and function in PVL male rats have been associated with raised estrogen levels in blood and in urine (11). In males, estrogen usually arises from the testes and the adrenals either by direct secretion or after "peripheral" conversion of androgenic precursors. This conversion occurs by aromatization of the steroid A ring of androgens $(18,19)$. Although the peripheral site(s) of androgen aromatization to estrogens is unclear (20-24), note that this process appears to be accelerated in men with chronic liver disease (25).

The present studies were undertaken to determine the source of raised serum estrogen levels in PVL rats as it seemed possible that portal bypass may be partially responsible for changes in sex steroid metabolism in chronic liver disease (11, 13). In PVL male rats, experiments were designed $(i)$ to elucidate the role of the testes as a source of raised serum estrogen concentrations, $(\mathrm{ii})$ to determine whether estradiol clearance was impaired, and (iii) to examine the disposition and metabolism of androstenedione.

1. Abbreviations used in this paper: $5 \alpha$-ADiol, $5 \alpha$-androstane- $3 \alpha, 17 \beta$ diol; $5 \beta$-ADiol, $5 \beta$-androstane- $3 \alpha, 17 \beta$-diol; DHT, $5 \alpha$-dihydrotestosterone; MCR, metabolic clearance rate; $\mathrm{X} \alpha \mathrm{OH}-\mathrm{AD}$ or $\mathrm{X} \beta \mathrm{OH}-\mathrm{AD}$, $\mathrm{X} \alpha$-hydroxyandrost-4-ene-3, 17-dione or $\mathrm{X} \beta$-hydroxyandrost-4-ene-3, 17-dione; PE, polyethylene tubing; PVL, portal vein ligated. 


\section{Methods}

\section{Animal model of portal bypass}

Wistar rats were bred and housed in the Animal House of the Institute for Clinical Pathology and Medical Research, Westmead Hospital. They were kept six to eight to a cage $(550 \times 370 \times 170 \mathrm{~mm})$ in conditions of constant temperature $\left(22^{\circ} \mathrm{C}\right)$, humidity, and lighting (12-h alternating light-dark cycle). Animals were allowed free access to water and food (commercial rat cubes).

Portal vein ligation was performed using the two stage procedure developed by Meredith and Wade (3) as described in detail elsewhere (4). In brief, stage 1 consisted of subcutaneous transposition of the spleen to facilitate development of perisplenic portasystemic anastomoses. At stage 2, performed 4 wk later, the portal vein was ligated above the confluence of the splenic and superior mesenteric veins. After a period of initial weight loss, PVL rats grew steadily, regaining their operative weight by $10-14 \mathrm{~d}$, and thereafter grew at the same rate as their littermates (4). Controls (littermates) were submitted to stage 1 and to sham laparotomy at the time of stage 2. Except where otherwise indicated, experiments were performed 6-8 wk after stage 2 .

\section{Measurement of plasma sex hormone levels}

Following an overnight fast, rats were anesthetized with ether and blood was collected by aortic puncture; the plasma was separated and stored frozen.

Testosterone. Testosterone was assayed in plasma by a radioimmunoassay that employed competitive binding of $\left[{ }^{125} \mathrm{I}\right]$ testosterone (102 $\mathrm{Ci} / \mathrm{mmol} \mathrm{sp} \mathrm{act)}$ with antibody bound to the solid phase (BIO-RIA, Louisville, KY). Testosterone standards (Sigma Chemical Co., St. Louis, MO.) were prepared in hormone-free rat serum. Cross-reactivity with other sex steroids was $<1 \%$ except for $5 \alpha$-dihydrotestosterone (DHT, $11 \%$ ). The between-assay coefficient of variation was $11.7 \%$.

Estrone and estradiol. Estrone and estradiol were assayed by radioimmunoassay using antisera obtained through Endocrine Sciences, Tarzana, CA. Estrone and estradiol standards were from Sigma Chemical Co., whereas $\left[{ }^{3} \mathrm{H}\right]$ estrone $(86.6 \mathrm{Ci} / \mathrm{mmol} \mathrm{sp}$ act $)$ and $\left[{ }^{3} \mathrm{H}\right]$ estradiol (102 Ci/mmol), from New England Nuclear, Boston, MA. The method used was essentially that of Wu and Lundy (26) except that column chromatography (27) was used to separate estrone and estradiol in plasma samples. Ethylene glycol was used as the stationary phase and the estrone fraction was eluted with $15 \%$ ethylacetate in isooctane. The sensitivity of the estrogen assays was $1 \mathrm{pg} / \mathrm{ml}$. The coefficient of variation for the estrone assay was $6.9 \%$ (at $20 \mathrm{pg} / \mathrm{ml}$ ) and for estradiol, $13 \%$ (at $10 \mathrm{pg} / \mathrm{ml}$ ). Cross-reactivity of the estradiol antiserum with estrone was $1.4 \%$ and of the estrone antiserum with estradiol, $5.8 \%$.

Androstenedione. Androstenedione was determined by radioimmunoassay using a method based on that of Coyotupa et al. (28). $\left[{ }^{3} \mathrm{H}\right]$ Androstenedione was added to the plasma before extraction, to correct for losses, and results were adjusted for extraction efficiency $(74 \pm 4.7 \%$, mean $\pm S D, n=42)$. Separation of androstenedione from other steroids was achieved by passage through mini "celite" columns essentially according to Thorneycroft et al. (29). The stationary phase used was propylene glycol and water $(95: 5, \mathrm{vol} / \mathrm{vol})$ rather than pure propylene glycol, and androstenedione was eluted with $3.5 \mathrm{ml} 15 \%$ benzene in isooctane.

\section{Effect of castration on plasma estrogen levels after PVL}

In this experiment, 12 male rats were subjected to portal vein ligation. $5 \mathrm{wk}$ after stage 2 , six rats were castrated whereas the remainder were submitted to a sham operation. $3 \mathrm{~d}$ later, and after an overnight fast, rats were anesthetized and blood was collected by aortic puncture for determination of plasma estrone and estradiol concentrations.

\section{Metabolic clearance rate (MCR) of sex steroids}

A constant infusion technique was used for determining the MCR of estradiol and androstenedione. Under ether anesthesia, rats were fitted with cannulas in the left internal jugular vein (polyethylene tubing 10 [PE-10]) and carotid artery artery (PE-50). In some experiments, a bile duct fistula was also created by inserting a cannula (PE-10) in the common bile duct after opening the abdomen through a midline incision; controls for these experiments were subjected to sham laparotomy with manipulation of the bile duct. Animals were allowed to regain consciousness and were then placed in restraining cages, maintained at $37^{\circ} \mathrm{C}$, and hydrated by intravenous infusion of $0.15 \mathrm{M} \mathrm{NaCl}$ at $1.2 \mathrm{ml} / \mathrm{h}$.

The following radiolabeled steroids were used: $\left[2,4,6,7-{ }^{3} \mathrm{H}\right]-$ estradiol $(99 \mathrm{Ci} / \mathrm{mmol}$ sp act; Amersham International, Amersham, UK) and $\left[1,2,6,7-{ }^{3} \mathrm{H}\right]$ androstenedione $(85 \mathrm{Ci} / \mathrm{mmol} \mathrm{sp}$ act; New England Nuclear). The purity of all radiolabeled steroids was at least $96 \%$, as determined by TLC in two different solvent systems.

Hormones were prepared for injection by evaporating the required volume of ${ }^{3} \mathrm{H}$-steroid to dryness under a stream of $\mathrm{N}_{2}$ and then dissolving the residuum in hormone-free rat plasma to produce a final concentration of $20 \mu \mathrm{Ci} / \mathrm{ml}$.

MCRs were determined by injecting rats with $10 \mu \mathrm{Ci}(0.5 \mathrm{ml}$ or $\sim 100 \mathrm{pmol}$ ) of radiolabeled steroid. $10 \mathrm{~min}$ later, an infusion of radiolabeled steroid prepared in hormone-free rat plasma was commenced. The radiolabeled steroids used for this purpose were prepared in an identical fashion as for bolus injection except that plasma was diluted 1:2 with $0.15 \mathrm{M} \mathrm{NaCl}$ to give a final concentration of 10 $\mu \mathrm{Ci} / \mathrm{ml}$. This solution was infused at a rate of $1 \mathrm{ml} / \mathrm{h}$, i.e., $10 \mu \mathrm{Ci} / \mathrm{h}$, using a calibrated constant infusion pump (Injectomat 30; Fresenius AG, Bad Homburg, FGR, or Drake Willock model 7420; Becton Dickinson \& Co., Portland, OR).

In preliminary experiments, it was demonstrated that plasma levels of each hormone achieved a steady plateau after 150-180 min (Fig. 1). In studies of MCR, three arterial blood samples were collected at 165 , 180 , and $195 \mathrm{~min}$. After extraction and separation of plasma steroids by TLC (see below), the plasma concentrations of radiolabeled hormones were determined by liquid scintillation spectrometry. MCR was calculated from the mean of plasma hormone concentrations at the three steady state time points according to the following relationship (30): $\mathrm{MCR}(\mathrm{ml} / \mathrm{min})=$ infusion $\mathrm{rate}(\mathrm{mol} / \mathrm{min}) /$ plasma concentration at steady state $(\mathrm{mol} / \mathrm{ml})$.

In experiments that examined the effect of bile fistulas on MCR of sex steroids, bile was collected into tared containers at 5-min intervals for $30 \mathrm{~min}$ and at $30-\mathrm{min}$ intervals thereafter up to $180 \mathrm{~min}$. The volume of bile was determined by weight, assuming a specific gravity of 1 .

\section{Separation of plasma and biliary steroids}

Steroid standards were obtained as follows: androstenedione, testosterone, estrone, estradiol, estriol, DHT, $5 \alpha$-androstane- $3 \alpha, 17 \beta$-diol ( $5 \alpha$-ADiol), $5 \beta$-androstane- $3 \alpha, 17 \beta$ diol (5$\beta$-ADiol), $6 \beta$-hydroxyan-

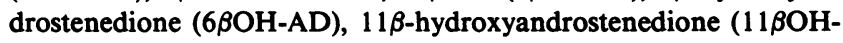
AD), $16 \alpha$-hydroxyandrostenedione (16 $\alpha \mathrm{OH}-\mathrm{AD}$ ) (all from Sigma Chemical Co.); $11 \alpha$-hydroxyandrostenedione (11 $\alpha \mathrm{OH}$-AD) (Steraloids Inc., Wilton, NH); 19-hydroxyandrostenedione (19OH-AD) (Syntex Inc., Palo Alto, CA); $7 \alpha$-hydroxyandrostenedione (7 $\alpha \mathrm{OH}$ $\mathrm{AD}), 6 \alpha$-hydroxyandrostenedione (6$\alpha \mathrm{OH}$-AD), $15 \alpha$-hydroxyandros-

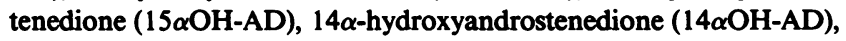
$2 \alpha$-hydroxyandrostenedione ( $2 \alpha \mathrm{OH}$-AD) (all provided by Professor $\mathrm{D}$. N. Kirk, Medical Research Council Steroid Reference Collection, Queen Mary's College, University of London, London, UK).

TLC was used to separate estrogens and androgens in samples of plasma or bile (31). Except in experiments designed to determine MCRs, steroid conjugates were first hydrolyzed by incubating an aliquot (usually $50 \mu \mathrm{l}$ ) of plasma or bile with a buffered solution of $\beta$-glucuronidase/sulfatase (from Helix pomatia type H-1; Sigma Chemical Co. $)(10 \mathrm{mg} / \mathrm{ml}$, in $0.2 \mathrm{M}$ acetate, $\mathrm{pH} 5.0)$ in a total volume of $1 \mathrm{ml}$. The incubation was for $3 \mathrm{~h}$ at $37^{\circ} \mathrm{C}$ in a shaking water bath. After hydrolysis, samples were extracted with $3 \mathrm{ml}$ ethylacetate for 15 min. A $0.5-\mathrm{ml}$ aliquot of the organic phase was placed in a scintillation vial, $10 \mathrm{ml}$ of Aquasol (New England Nuclear, or DuPont Co., Wil- 
Table I. Plasma Sex Steroids in PVL and in Control Male Rats

\begin{tabular}{lllll}
\hline Group & Estrone & Estradiol & Testosterone & Androstenedione \\
\hline & pmol/liter & pmol/liter & nmol/liter & $n$ mol/liter \\
PVL $(n)$ & $97.3 \pm 23.3(19)$ & $27.5 \pm 13.6(20)$ & $0.80 \pm 0.17(6)$ & $0.44 \pm 0.35(14)$ \\
Control $(n)$ & $68.5 \pm 23.3(17)$ & $12.5 \pm 8.4(17)$ & $5.79 \pm 4.20(6)$ & $0.45 \pm 0.27(17)$ \\
$P$ value & $<0.001$ & $<0.001$ & $<0.001$ & NS \\
\hline
\end{tabular}

Values are given as mean $\pm \mathrm{SD} ; n$, number of animals studied.

mington, DE) was added and the radioactivity was determined in a liquid scintillation spectrometer. The remaining $2.0 \mathrm{ml}$ of organic phase was evaporated to dryness under a stream of $\mathrm{N}_{2}$. Before TLC, the residuum was dissolved in $2 \times 50 \mu \mathrm{l}$ chloroform and spotted onto a 20 $\times 20 \mathrm{~cm}$ silica gel TLC plate (E. Merck, Darmstadt, FRG; SG60 type F254 indicator). Plates were run twice in chloroform:ethyl acetate (80:20, vol/vol) (System 1) (31). Since this system did not adequately resolve some groups of androstenedione hydroxylated metabolites, samples were also subjected to TLC using chloroform:ethylacetate $(1: 2, \mathrm{vol} / \mathrm{vol})$ (System 2) (32). Steroid standards were run in adjacent lanes on each plate. Recognition of standards was by fluorescence under ultraviolet light and this was confirmed by staining with $10 \%$ phosphomolybdic acid. Bands corresponding to hormone standards were scraped into scintillation vials to which $10 \mathrm{ml}$ Aquasol was added before determination of radioactivity by liquid scintillation spectrometry. Results were expressed as the percentage of radioactivity recovered from the plate. Except in the case of the $E_{2}$ infusion experiments, the overall recovery of steroids after extraction from bile and plasma by ethylacetate and separation by TLC was $75 \pm 5 \%(n=49)$. For reasons which remain unclear, it was only possible to extract a small and rather variable amount (15-30\%) of radioactivity from plasma obtained during $\left[{ }^{3} \mathrm{H}\right]$-estradiol infusion. To provide a more accurate method of correcting for possible losses of unmetabolized $\mathrm{E}_{2},\left[{ }^{14} \mathrm{C}\right]$ estradiol $(10,000 \mathrm{dpm})$ was added to each sample, and the recovery of $\left[{ }^{14} \mathrm{C}\right]-$ estradiol after extraction and TLC separation of samples were calculated using a double-label counting technique (33).

The percentage of each steroid excreted in bile during infusion of $\left[{ }^{3} \mathrm{H}\right]$ androstenedione was calculated as the area under the concentration-time curve from 0 to $180 \mathrm{~min}$ by employing the trapezoidal rule and using a desktop computer (HP 85); Hewlett-Packard Co., Palo Alto, CA).

\section{Statistical analysis}

Differences between groups were evaluated by the Student's $t$ test (unpaired, two-tailed), with $P<0.05$ indicating a significant difference between means.

\section{Results}

Changes in plasma sex steroids in PVL male rats and the effects of castration

Six wk after PVL, there was an $85 \%$ decrease in serum testosterone concentration and a twofold increase in serum estradiol concentration while serum estrone levels were also increased (Table I). In contrast, there was no change in serum androstenedione levels (Table I). Castration performed after PVL had no effect on levels of estrone and estradiol after portal bypass (Table II).

\section{MCR of estradiol}

During constant infusion of $\left[{ }^{3} \mathrm{H}\right]$ estradiol, plateau levels of radioactivity were achieved by $120 \mathrm{~min}$ (Fig. 1). After extrac- tion and TLC of plasma samples, essentially all radioactivity migrated with the authentic estradiol standard. The percentage recovery of $\left[{ }^{14} \mathrm{C}\right]$ estradiol added to each plasma sample was $55 \pm 22 \%$. This recovery factor was used to estimate the true $\left[{ }^{3} \mathrm{H}\right]$ estradiol concentrations in postinfusion samples, and this value was used to calculate the MCR of estradiol.

Diversion of bile via a biliary fistula did not appear to effect MCR of estradiol in the 3-h infusion experiment (data not shown). The bile duct fistula rats and their sham-operated controls were therefore considered together in the comparison between PVL and control rats. There was no significant difference in MCR of estradiol between PVL rats and controls whether expressed in absolute terms (milliliters per minute) or per gram of liver (Table III).

\section{$M C R$ of androstenedione}

During infusion of $\left[{ }^{3} \mathrm{H}\right]$ androstenedione, plasma levels of $\left[{ }^{3} \mathrm{H}\right]$ androstenedione reached a plateau after $150 \mathrm{~min}$ (Fig. 1). Separation of unmetabolized androstenedione from other steroids by TLC allowed determination of the MCR of androstenedione. This was similar in PVL and control rats when expressed in absolute terms (milliliters per minute) or per unit mass of liver (Table III). Biliary diversion did not appear to alter the MCR of androstenedione in either PVL or control rats (data not shown).

\section{Metabolic fate of infused $\left[{ }^{3} \mathrm{H}\right]$ androstenedione}

There was extensive metabolism of the infused androstenedione during the 180-min experiment. The profile of resultant ${ }^{3} \mathrm{H}$-labeled steroids present in plasma at $180 \mathrm{~min}$ is illustrated in Fig. 2. There was a higher proportion of total hydroxylated androstenedione metabolites in plasma from PVL rats as compared with controls $(P<0.001$, Fig. 2$)$. However, this change was not uniform among the individual metabolites. In

Table II. Plasma Estrogens in PVL Male and in PVL Male Rats after Castration

\begin{tabular}{lll}
\hline Group & Estrone & Estradiol \\
\hline & pmol/liter & pmol/liter \\
PVL $(n=6)$ & $80.1 \pm 19.4$ & $60.2 \pm 9.2$ \\
PVL + castration $(n=6)$ & $83.8 \pm 29.7$ & $60.6 \pm 10.1$ \\
$P$ value & NS & NS
\end{tabular}

This experiment was performed on different litters of rats than those used in earlier experiments. This is presumed to be the reason for different values in the PVL group compared with Table I. $n$, the number of animals studied. 

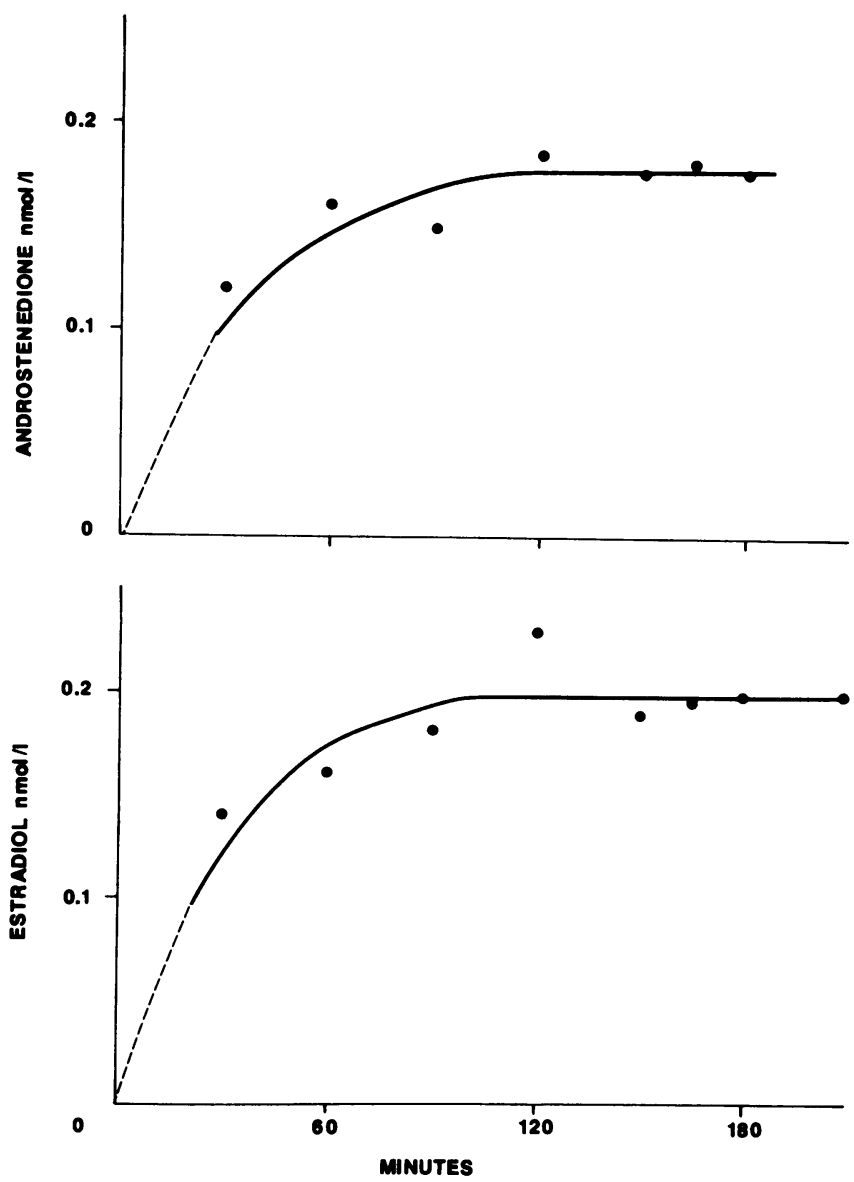

Figure 1. Plasma concentrations of $\left[{ }^{3} \mathrm{H}\right]$ androstenedione (top) and $\left[{ }^{3} \mathrm{H}\right]$ estradiol (bottom) during constant infusion of respective radiolabeled steroid hormones. Values are mean of three experiments. Details of loading doses and infusion rates are described in Methods.

PVL rats, the proportions of $11 \beta O H-A D$ and material that co-migrated with $5 \alpha$-ADiol were significantly increased in plasma compared with controls, whereas no increase was observed in the formation of $6 \beta \mathrm{OH}-\mathrm{AD}, 16 \alpha \mathrm{OH}-\mathrm{AD}$, and material that co-migrated with $5 \beta$-ADiol.

Whereas plasma androstenedione and testosterone levels appeared to be lower in PVL rats during infusion of $\left[{ }^{3} \mathrm{H}\right]-$ androstenedione, there was a sevenfold greater conversion to estradiol so that this steroid accounted for $15 \%$ of the plasma radiolabel in PVL rats (Fig. 2). Rather surprisingly, there was no increase in the proportion of plasma estrone or estriol derived from infused androstenedione in PVL rats. Levels of DHT were also increased in PVL rats, but this represented $<3 \%$ of total plasma radioactivity.
Because accumulation of steroid metabolites in plasma could reflect enhanced production and/or decreased elimination, the excretion of ${ }^{3} \mathrm{H}$-steroids in bile was also determined during $\left[{ }^{3} \mathrm{H}\right]$ androstenedione infusion. The metabolic changes suggested by the plasma data were attested for by the bile data. Whereas estradiol formed from infused androstenedione represented $<3 \%$ of the total radioactivity in bile from normal rats, it was the major biliary steroid in PVL rats accounting for $25-46 \%$ of excreted radioactivity during $180 \mathrm{~min}$ (Fig. 3). In contrast, estrone excretion appeared unaltered. The proportion of radioactivity excreted in bile as estriol was significantly less in PVL rats at almost every time point; however, the area under the curve of estriol excretion against time failed to reach statistical significance (Fig. 3, Table IV).

There were also distinct differences in the amounts of individual androstenedione hydroxylated metabolites excreted in bile during constant infusion of $\left[{ }^{3} \mathrm{H}\right]$ androstenedione. The excretion of $7 \alpha \mathrm{OH}-\mathrm{AD}$ was unchanged but that of $16 \alpha \mathrm{OH}-\mathrm{AD}$ $(P<0.02), 6 \beta O H-A D(N S)$, and material that co-chromatographed with $5 \beta$-ADiol $(P<0.05)$ appeared to be reduced. In contrast, material that co-migrated with the $5 \alpha$-ADiol metabolite was excreted in significantly greater amounts of PVL rats as compared with controls (Fig. 3, Table IV). Finally, testosterone and DHT formation appeared to be increased in PVL rats, as indicated by biliary excretion.

\section{Discussion}

These studies in the intact PVL male rat show that striking and hitherto unsuspected changes in the metabolism of androstenedione most likely account for increased estradiol production after portal bypass. The present findings are also inconsistent with several alternative sources of raised serum estrogens.

A major site of estrogen secretion in the male rat is testicular tissue. It is thus of interest that important changes in the hypothalamic-pituitary-gonadal axis occur after portal bypass $(11,17)$. However, in the present study it was demonstrated that castration of PVL male rats did not lower the elevated serum estrogen levels that were observed. This finding excluded the possibility that the testes were the source of enhanced estrogen production in male rats after portal bypass.

It also seemed possible that serum estrogen concentrations may be raised as the consequence of impaired hepatic clearance of estrone and estradiol. It is well-established that the liver is an important site for removal of estradiol from blood $(34,35)$. Since the hepatic extraction of estradiol is avid, it might be anticipated that a reduction in total hepatic blood flow, such as occurs with portal bypass, would result in decreased hepatic clearance of estradiol (34-37). Moreover, it seems likely that estradiol undergoes an enterohepatic circula-

Table III. MCR of Estradiol and Androstenedione in Portal Vein Ligated Male Rats and in Controls

\begin{tabular}{lllll}
\hline Group & MCR-estradiol & \multicolumn{3}{c}{ MCR-androstenedione } \\
\hline & ml/min & ml/min per g liver & ml/min & $\mathrm{ml} / \mathrm{min}$ per g liver \\
PVL $(n)$ & $2.19 \pm 1.16(7)$ & $0.25 \pm 0.15(7)$ & $11.7 \pm 9.12(10)$ & $1.76 \pm 1.42(10)$ \\
Control $(n)$ & $2.07 \pm 0.93(7)$ & $0.22 \pm 0.11(7)$ & $18.1 \pm 13.3(9)$ & $1.53 \pm 1.26(9)$ \\
\hline
\end{tabular}

None of the differences between control and PVL groups are significant $(P>0.05)$. Values are given as mean \pm SD. $n$, the number of animals studied. 


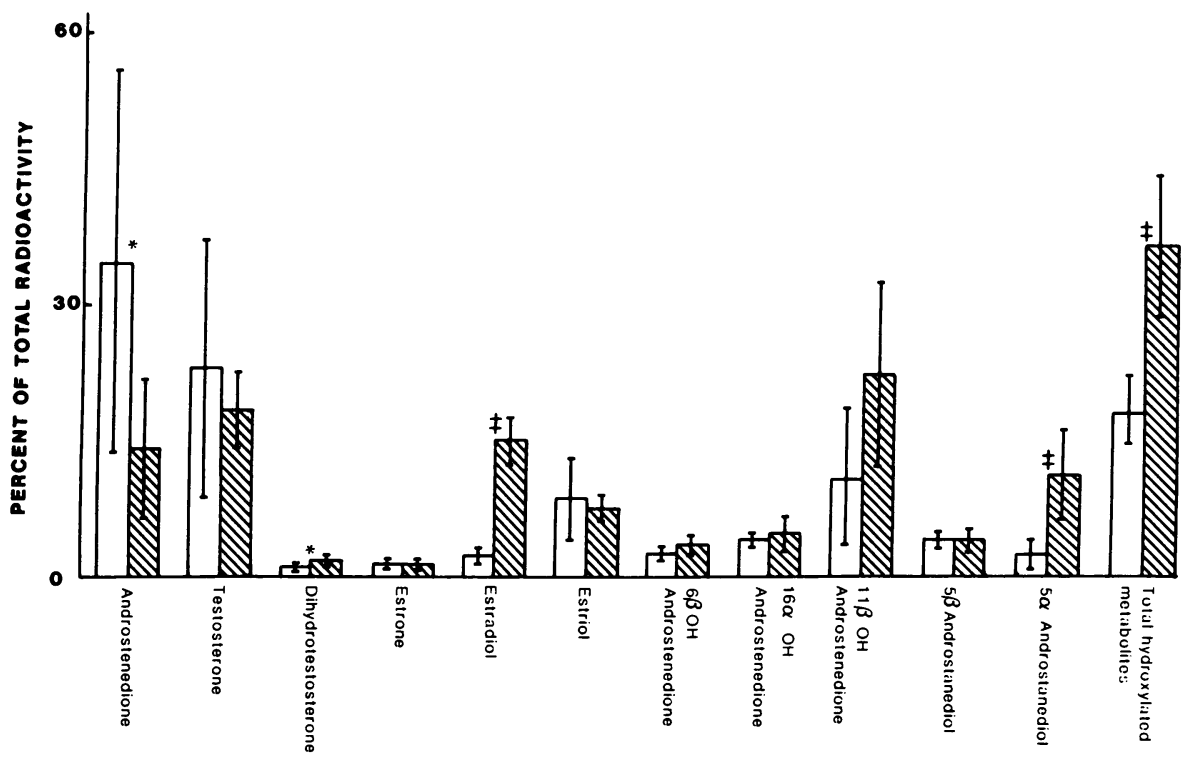

Figure 2. Profile of ${ }^{3} \mathrm{H}$-labeled plasma steroids after $\left[{ }^{3} \mathrm{H}\right]$ androstenedione infusion for 180 min (see Methods). Data from control rats is indicated by open columns and that from PVL rats by hatched columns; small bars indicate one standard deviation from the mean. $* P<0.05, \ddagger P<0.01$; where not otherwise indicated, apparent differences between groups are not significant. tion $(35,37)$. Interruption of the hepatic delivery of gut-derived estradiol with shunting to the systemic circulation (the results of portal bypass) could also impair hepatic estradiol clearance. However, the present results show no significant reduction in estradiol clearance in the PVL rat. Biliary damage did not appear to enhance estradiol clearance in PVL or in normal rats, a finding that implies that there is no significant net recirculation of estradiol during the time of this experiment. These observations, in a model of portal bypass without parenchymal liver disease, are an important extension of earlier studies in humans with cirrhosis from which similar conclusions were derived $(14,37)$. The previous concept that estrogens accumulate in chronic liver disease as portasystemic shunting and interruption of the enterohepatic circulation impair their hepatic excretion (34) now seems unlikely.

Another mechanistic explanation for the raised estrogen levels observed in chronic liver disease with portal bypass is that weak androgens accumulate and act as the substrate for "peripheral" aromatization to estrogens $(16,17)$. The term peripheral conversion is used with reference to a site external to an endocrine organ, but the precise location of aromatase activity is unclear (20-24). It has been reported that serum androstenedione levels are increased in men with chronic liver disease $(15,25)$, and it had been assumed that a similar phenomenon occurs in rats as the consequence of portal bypass $(13,16,17)$. The present findings are not consistent with this mechanism because serum androstenedione levels were not elevated in the PVL male rat. Also, there was no impairment of the MCR of androstenedione. Hence, production rates of androstenedione must also be normal in this rat model of portal bypass.

A qualitative difference in androstenedione metabolism in the PVL male rat was indicated by the increased proportion of hydroxylated androstenedione metabolites that accumulated in plasma during androstenedione infusion. Furthermore, there were major differences in the individual pathways of androstenedione hydroxylation. As reflected by the biliary profiles of hydroxylated androstenedione metabolites, the $16 \alpha$ - and $6 \beta$-hydroxylation pathways were reduced by $50-70 \%$ whereas the $7 \alpha$-hydroxylation pathway was unaltered. In the liver, the stereospecific hydroxylation of androstenedione is catalyzed by separate forms of $P-450(32,38-41)$. Thus, the $7 \alpha$-hydroxylation of androstenedione is catalyzed exclusively by $P-450$ form a (in the nomenclature of Levin et al. [30]; this $P-450$ is termed UT-F by Guengerich et al. [41]). Androstenedione $16 \alpha$-hydroxylation is catalyzed in untreated rat liver by the male-specific form $h(42,43)$, also termed $P-450_{\text {Ut-A }}(40$, 41 ), and the $6 \beta$-hydroxylase pathway is attributable either to $P-450$ form $\mathrm{g}(42)$ or to the principal pregnenolone $16 \alpha$-carbonitrile-inducible form, $P-450_{\mathrm{PCN} / \mathrm{E}}(41)$. It is now known that $P-450_{\mathrm{PCN} / \mathrm{E}}$ is also sexually differentiated (male specific) in untreated rat hepatic microsomes. Forms UT-A and PCN/E are both active in the $N$-demethylation of ethylmorphine (41, 42). Hence, the present finding that both the $16 \alpha$ - and $6 \beta$-steroid hydroxylation pathways are decreased in the PVL male rat are consistent with our earlier observation that microsomal ethylmorphine $N$-demethylase activity is decreased after portal bypass $(4,11)$.

We have recently demonstrated that levels of form UT-A are extremely low in hepatic microsomes from male rats with experimental cirrhosis (44). A common characteristic feature of cirrhosis is portal hypertension and portal bypass, and the findings of the present study raise the intriguing possibility that major changes in drug and steroid metabolism in cirrhosis (at least in rats) may be due to altered regulation of particular forms of $P-450$ as the consequence of portal bypass.

It is apparent from the observations that plasma estradiol levels are raised and metabolic clearance of estradiol is normal that the production rate of estradiol must be increased after portal bypass in male rats. With regard to the source of raised serum estrogens in portal bypass, the most important observation of the present study is that there is a 7- to 15-fold increase in conversion of androstenedione to estradiol in the PVL male rat. If biliary excretion of metabolites can be taken as a reliable criterion (and the plasma profile was qualitatively similar), $\sim 25-46 \%$ of infused androstenedione is converted to estradiol. Assuming that endogenous androstenedione follows a similar disposition, this could account for most if not all of the increase in plasma and urinary estradiol levels in the PVL male rat. 

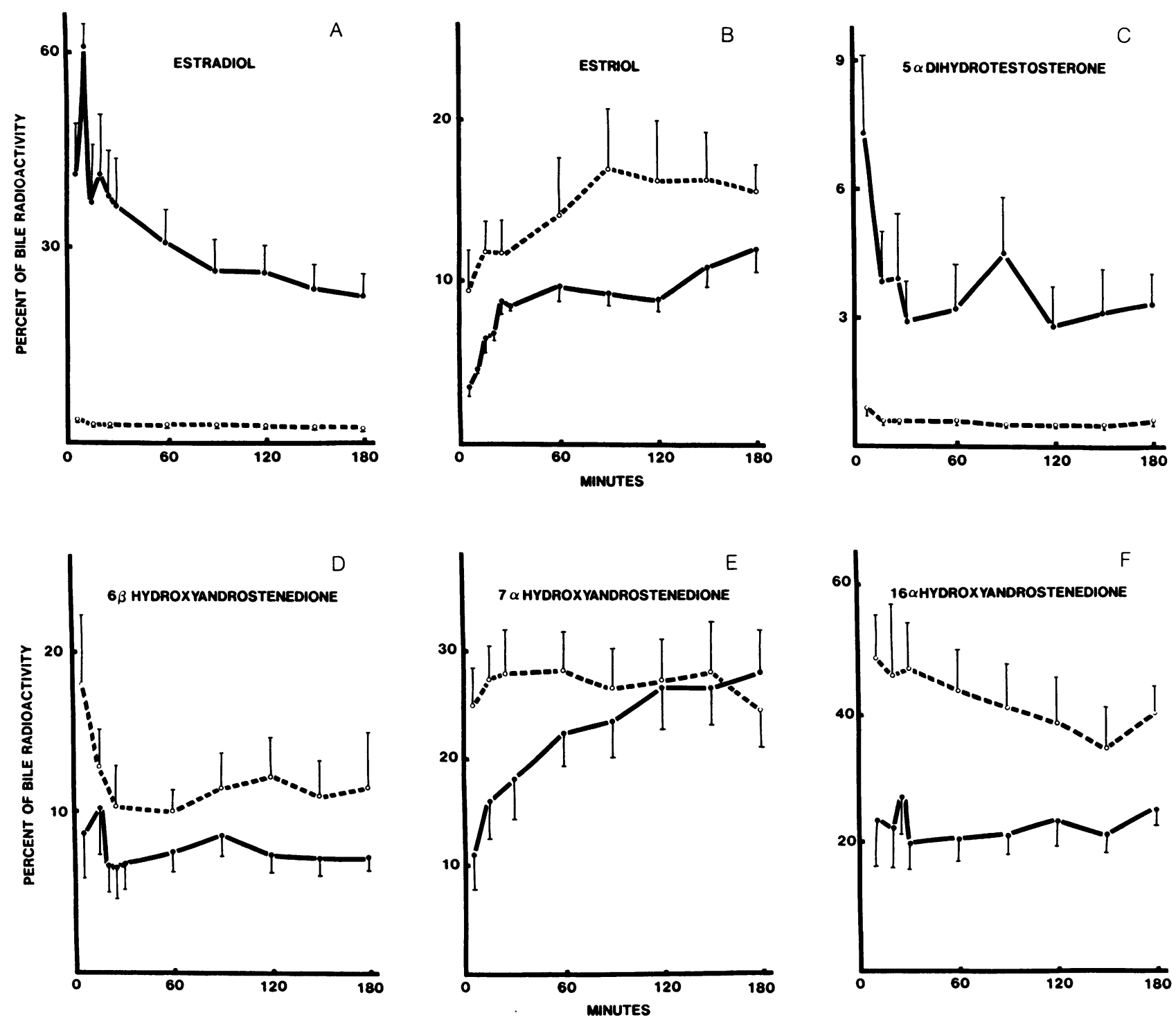

Figure 3. Biliary excretion of hormones and metabolites formed from infused $\left[{ }^{3} \mathrm{H}\right]$ androstenedione. The loading dose and intravenous infusion rate of $\left[{ }^{3} \mathrm{H}\right]$ androstenedione are indicated in Methods. Data are expressed as percentage of radiolabel recovered from bile samples at times indicated; the total proportion of infused radiolabel recovered in bile during 180 min was the same in control (- - - - )

A surprising observation in relation to the increased estradiol production from androstenedione in PVL rats was that there was no increase in estrone production. Estrone is usually the major product of steroid A ring aromatization of androstenedione $(15,16,18-20,24,25,30)$. Greatly increased estradiol production might have occurred because the $17 \beta$-oxidoreductase pathway that converts estrone to estradiol is more active after PVL or because testosterone (which was formed from androstenedione in greater amounts in PVL rats as compared with controls) served as the preferred substrate for aromatase (aromatization of testosterone results in estradiol) (15, $16,20,24,25,30)$. However, a third possibility, which is consistent with the present data, is that estriol formation (from androstenedione) is actually reduced in PVL male rats. The third hydroxyl substituent of estriol is in the $16 \alpha$-position of and portal vein ligated (- - ) rats and ranged from 27 to $52 \%$. $(A)$

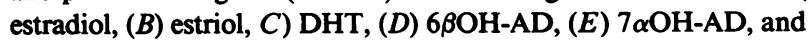
(F) $16 \alpha \mathrm{OH}-\mathrm{AD}$. The data are derived from six PVL and five control rats. Vertical bars indicate one standard error from the mean. Note the different scales for the ordinate in each panel.

the steroid nucleus and therefore the question arises as to whether the male-specific $16 \alpha$-hydroxylase $P-450_{\mathrm{UT}-\mathrm{A}}$ is active in the conversion of estradiol to estriol. Certainly androstenedione $16 \alpha$-hydroxylase activity is greatly diminished after portal bypass and it would appear consistent that impaired activity of this enzyme may well result in raised serum levels of estradiol after portal bypass.

The increased formation of estradiol from androstenedione, which was observed in the intact animal, leads us to conclude that altered hepatic metabolism of androstenedione accounts for the increased estradiol production associated with portal bypass. Accumulation of androstenedione as substrate for aromatization does not appear to occur and the MCR of estradiol is not altered. The changes in sex-dependent pathways of androstenedione hydroxylation suggest to us the possi- 


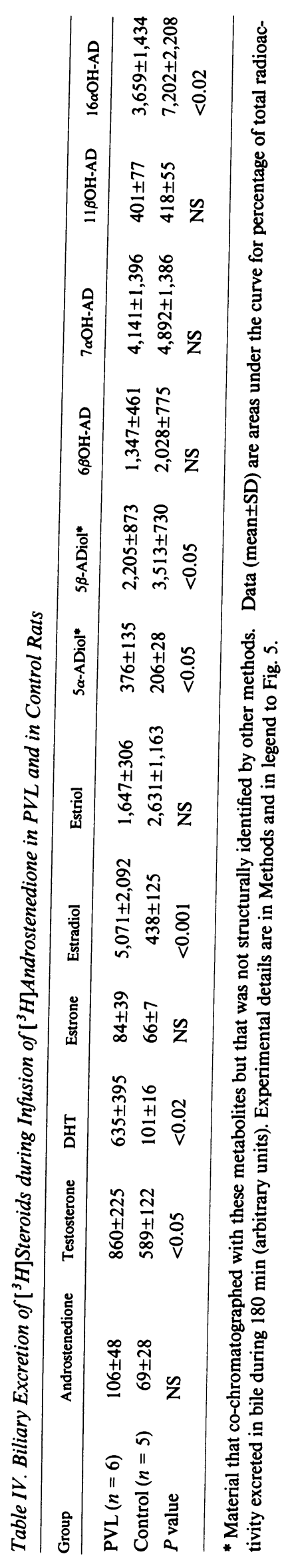

bility that feminization of $\mathrm{C}_{19}$ steroid metabolism may occur in portal bypass. The sex-dependent hepatic $P-450$ isoforms involved with sex steroid metabolism are under hypothalamic-pituitary-gonadal control (45-48). It is also known that release of some pituitary hormones is altered in rats with portal bypass $(11,13)$ as well as in humans with cirrhosis (17). Hence, abnormalities of neuroendocrine function that result from portal bypass may result in the observed changes in hepatic drug and steroid metabolism.

\section{Acknowledgments}

We thank Helen Theile of the Endocrinology Laboratory, Prince of Wales Hospital, Sydney, Australia, for her assistance with the androstenedione radioimmunoassay, and Diane West and Athena Webster for typing the manuscript. Linda Frost provided valuable technical assistance.

This research was supported by the Australian National Health and Medical Research Council and the Bortolussi Liver Research Trust Fund of the Westmead Hospital.

\section{References}

1. Popper, H., H. Elias, and D. E. Petty. 1952. Vascular pattern of the cirrhotic liver. Am. J. Clin. Pathol. 22:717-729.

2. Gross, G., and C. V. Perrier. 1975. Intrahepatic porta-systemic shunting in cirrhotic patients. N. Engl. J. Med. 293:1046-1047.

3. Meredith, C. G., and D. N. Wade. 1981. A model of portal-systemic shunting in the rat. Clin. Exp. Pharmacol. Physiol. 8:651-652. (Abstr.)

4. Farrell, G. C., and L. Zaluzny. 1983. Portal vein ligation selectively lowers hepatic cytochrome P-450 levels in rats. Gastroenterology. 85:275-282.

5. Ossenberg, F.-W.., L. Pointard, and J.-P. Benhamou. 1972. Effect of portacaval shunt on hepatic cytochrome P-450 in rats. Rev. Eur. Etud. Clin. Biol. 17:791-793.

6. Lauterburg, B. H., V. Sautter, R. Preisig, and J. Bircher. 1976. Hepatic functional deterioration after portacaval shunt in the rat. Gastroenterology. 71:221-227.

7. Pector, J.-C., J. Winward, J.-P. Dehaye, and J. Christophe. 1980. Effects of portacaval shunt and transposition on fatty acid and cholesterol biosynthesis in rat liver. Am. J. Physiol. 239:G83-G89.

8. Rubin, E., F. Hutterer, T. Ohshiro, and J. H. Jacobson. 1968. Effect of experimental portacaval shunt on hepatic drug metabolising enzymes. Proc. Soc. Exp. Biol. Med. 127:444-447.

9. Pector, J. C., F.-W. Ossenberg, M. Peignoux, and J.-P. Benhamou. 1975. The effect of portacaval transposition on hepatic cytochrome P-450 in the rat. Biomedicine (Paris). 23:160-162.

10. Hirokata, Y., S. Tong, Z. H. Siddik, M. A. Trush, E. G. Mimnaugh, and T. E. Gram. 1982. Sex-dependent differences in the effects of portacaval anastomosis on hepatic monooxygenases in rats. Biochem. Pharmacol. 31:499-502.

11. Farrell, G. C., A. Koltai, L. Zaluzny, and M. Murray. 1986. Effects of portal vein ligation on sex hormone metabolism in male rats: relationship to lowered hepatic cytochrome P-450 levels. Gastroenterology. 90:299-305.

12. Kato, R. 1974. Sex-related differences in drug metabolism. Drug Metab. Rev. 3:1-32.

13. Van Thiel, D. H., J. S. Gavaler, C. F. Cobb, and C. J. McLain. 1983. An evaluation of the respective roles of portasystemic shunting and portal hypertension in rats upon the production of gonadal dysfunction in cirrhosis. Gastroenterology. 85:154-159.

14. Baker, H. W. G., H. G. Burger, D. M. de Kretser, A. Dulmenus, B. Hudson, S. O'Connor, C. A. Paulsen., N. Purcell, G. C. Rennie, C. S. Seah, H. P. Taft, and C. Wang. A study of the endocrine manifestations of cirrhosis. Q. J. Med. 45:145-178. 
15. Green, J. R. B. 1977. Mechanism of hypogonadism in cirrhotic males. Gut. 18:843-853.

16. Van Thiel, D. H. 1982. Endocrine function. In The Liver: Biology and Pathobiology. I. M. Arias, H. Popper, D. Schachter, and D. A. Shafritz, editors. Raven Press, New York. 717-744.

17. Van Thiel, D. H., J. S. Gavaler, and R. R. Schade. 1985. Liver disease and the hypothalamic pituitary gonadal axis. Semin. Liver Dis. 5:35-45.

18. Thompson, Jr., E. A., and P. K. Suteri. 1971. Utilization of oxygen and reduced nicotinamide adenine dinucleotide phosphate by human placental microsomes during aromatization of androstenedione. J. Biol. Chem. 249:5364-5372.

19. Miyairi, S., and J. Fishman. 1985. Radiometric analysis of oxidative reactions in aromatization by placental microsomes. J. Biol. Chem. 260:320-325.

20. Longcope, C., T. Kato, and R. Horton. 1969. Conversion of blood androgens to estrogens in normal adult men and women. J. Clin. Invest. 48:2191-2201.

21. Longcope, C., R. B. Billiar, Y. Takaoka, P. S. Reddy, D. Richardson, and B. Little. 1983. Tissue sites of aromatization in the female rhesus monkey. Endocrinology. 113:1679-1682.

22. Nimrod, A., and K. J. Ryan. 1975. Aromatization of androgens by human abdominal and breast fat tissue. J. Clin. Endocrinol. Metab. 40:367-372.

23. Smuk, M., and J. Schwers. 1977. Aromatization of androstenedione by human adult liver in vitro. J. Clin. Endocrinol. Metab. 45:1009-1012.

24. Schindler, A. E. 1975. Steroid metabolism of fetal tissues. II. Conversion of androstenedione to estrone. Am. J. Obstet. Gynecol. 123:265-268.

25. Gordon, G. G., J. Olivo, F. Rafii, and A. L. Southren. 1975. Conversion of androgens to estrogens in cirrhosis of the liver. J. Clin. Endocrinol. Metab. 40:1018-1026.

26. Wu, C., and L. E. Lundy. 1971. Radioimmunoassay of plasma estrogens. Steroids. 18:91-111.

27. Abraham, G. E., J. E. Bustler, L. A. Lucas, P. C. Corrales, and R. C. Teller. 1972. Chromatographic separation of steroid hormones for use in radioimmunoassay. Anal. Lett. 5:509-517.

28. Coyotupa, J. A., F. Parlow, and G. E. Abraham. 1973. Simultaneous radioimmunoassay of plasma testosterone and dihydrotestosterone. Anal. Lett. 5:329-339.

29. Thorneycroft, I. H., W. O. Ribeiro, S. C. Stone, and S. A. Tillson. 1973. A radioimmunoassay of androstenedione. Steroids. 21:111-122.

30. Horton, R., and J. F. Tait. 1966. Androstenedione production and interconversion rates measured in peripheral blood and studies on the possible site of its conversion to testosterone. J. Clin. Invest. 45:301-313.

31. Ruh, T. S. 1976. Simultaneous separation of estrogens and androgens using thin-layer chromatography. J. Chromatogr. 121:8284.

32. Waxman, D. J., A. Ko, and C. Walsh. 1983. Regioselectivity and stereoselectivity of androgen hydroxylations catalyzed by cytochrome P-450 isozymes purified from phenobarbital-induced rat liver. J. Biol. Chem. 258:11937-11947.
33. Farrell, G. C., J. L. Gollan, and R. Schmid. 1980. Efflux of bilirubin into plasma following hepatic degradation of exogenous heme. Proc. Soc. Exp. Biol. Med. 163:504-509.

34. Aldercreutz, H. 1970. Oestrogen metabolism in liver disease. $J$. Endocrinol. 46:129-163.

35. Back, D. J., A. M. Breckenridge, F. E. Crawford, M. Giles, M. L'E. Orme, and P. H. Rowe. 1981. The pharmacokinetics of oestrone sulphate in the rat. J. Steroid Biochem. 14:1045-1047.

36. Van Thiel, D. H., J. S. Gavaler, C. Wight, W. I. Smith, Jr., and J. Abuid. 1978. Thyrotropin-releasing hormone (TRH)-induced growth hormone (hGH) responses in cirrhotic men. Gastroenterology. 75:66-70.

37. Olivo, J., G. G. Gordon, F. Rafii, and A. L. Southren. 1975 Estrogen metabolism in hyperthyroidism and cirrhosis of the liver. Steroids. 26:47-56.

38. Wood, A. W., D. E. Ryan, P. E. Thomas, and W. Levin. 1983. Regio- and stereo-selective metabolism of two $\mathrm{C} 19$ steroids by five highly purified and reconstituted rat hepatic cytochrome P-450 isozymes. J. Biol. Chem. 258:8839-8847.

39. Cheng, K-C., and J. B. Schenkman. 1983. Testosterone metabolism by cytochrome P-450 isozymes $R_{L} M_{3}$ and $R L M_{5}$ and by microsomes. J. Biol. Chem. 258:11738-11744.

40. Waxman, D. J. 1984. Rat hepatic cytochrome P-450 isoenzyme 2C: identification as a male-specific, developmentally induced steroid $16 \alpha$-hydroxylase and comparison to a female-specific cytochrome P-450 isoenzyme. J. Biol. Chem. 259:15481-15490.

41. Waxman, D. J., G. A. Dannan, and F. P. Guengrich. 1985. Regulation of rat hepatic cytochrome P-450: age-dependent expression, hormonal imprinting, and xenobiotic inducibility of sex-specific isoenzymes. Biochemistry. 24;4409-4417.

42. Ryan, D. E., S. Iida, A. W. Wood, P. E. Thomas, C. S. Lieber, and W. Levin. 1984. Characterization of three highly purified cytochromes P-450 from hepatic microsomes of adult male rats. J. Biol. Chem. 259:1239-1250.

43. Morgan, E. T., C. MacGeoch, and J.-Å. Gustafsson. 1985. Sexual differentiation of cytochrome $\mathrm{P}-450$ in rat liver: evidence for a constitutive isozyme as the male-specific $16 \alpha$-hydroxylase. Mol. Pharmacol. 27:471-479.

44. Murray, M., L. Zaluzny, G. A. Dannan, F. P. Guengerich, and G. C. Farrell. 1987. Altered regulation of cytochrome P-450 enzymes in choline-deficient cirrhotic male rat liver. Mol. Pharmacol. 31:117121.

45. Morgan, E. T., C. MacGeoch, and J.-Å. Gustafsson. 1985. Hormonal and developmental regulation and expression of the hepatic microsomal $16 \alpha$-hydroxylase cytochrome $\mathrm{P}-\mathbf{4 5 0}$ apoprotein in the rat. J. Biol. Chem. 260:11895-11898.

46. Gustafsson, J.-Å., A. Mode. G. Norstedt, and P. Skett. 1983. Sex steroid induced changes in hepatic enzymes. Annu. Rev. Physiol. 45:51-60.

47. Mode, A., J.-Å. Gustafsson, J.-O. Jansson, S. Eden, and O. Isaksson. 1982. Association between plasma level of growth hormone and sex differentiation of hepatic steroid metabolism in the rat. Endocrinology. 111:1692-1697.

48. MacGeoch, C., E. T. Morgan, and J.-Å. Gustafsson. 1985. Hypothalamic-pituitary regulation of cytochrome $\mathrm{P}-450$ apoprotein levels in rat liver. Endocrinology. 117:2085-2092. 